\title{
A Controlled, Randomized, Double-blind Trial to Evaluate the Effect of Vegetables and Whole Grain Powder That Is Rich in Dietary Fibers on Bowel Functions and Defecation in Constipated Young Adults
}

\author{
Hye-Im Woo, Shin Hye Kwak, Yeojin Lee, Ji Hee Choi, Young Mi Cho, Ae-Son Om
}

Laboratory of Food Safety and Toxicology, Department of Food and Nutrition, College of Human Ecology, Hanyang University, Seoul, Korea

\begin{abstract}
Background: This study evaluated the effect of vege-powder (VP), mainly consisted of chicory, broccoli, and whole grains, on bowel habit improvement and constipation alleviation.

Methods: Using the Roman standard II, 96 male and female subjects in their twenties with constipation symptoms were divided into a control group or VP group. Subjects in a control group were supplied with rice flakes-powder (RFP) and subjects in the VP group were provided with $30 \mathrm{~g}$ of VP twice daily for 4 weeks. Constipation relief effectiveness was surveyed on 5-point Likert scales depending on stool hardness, amount of stool, sensation of incomplete evacuation, and straining to defecate at day 0,14 , and 28 of RFP or VP intake. Results: Repeated measures analysis of variance analysis revealed that VP intake caused significant temporal changes in stool hardness, amount, sensation of incomplete evacuation, and straining to defecate. In addition, significant differences between control and VP groups were found in stool hardness, amount, sensation of incomplete evacuation, and straining to defecate at day 14 and 28 of experimental diet consumption. VP supplement for 2 weeks significantly increased the evacuation frequency $(1.04 \pm 0.71)$, compared to control group $(0.41 \pm 0.64)$ and this increase was maintained at 4 week of diet supplements.

Conclusions: This result showed that constipated subjects who consumed VP, mainly consisting of chicory, broccoli, and whole grains, improved constipation symptoms at 2 and 4 weeks of consumption compared to those of control group who were provided with RFP. (J Cancer Prev 2015;20:64-69)
\end{abstract}

Key Words: Whole grain, Dietary fiber, Vegetable powder, Defecation, Constipation

\section{INTRODUCTION}

Constipation is medically diagnosed when patients defecate less than 2 times a week, have difficult or infrequent passage of stool, pass severely hardened stool, or have sensation of incomplete evacuation for over 3 months. The constipation is classified into primary and secondary causes. The primary cause includes severe decrease in physical activity or insufficient fiber intake, and the secondary includes other various illnesses (e.g., Parkinson's disease). ${ }^{1}$

Constipation is not life threatening however when the symptoms persist over a long period of time, it could lead to improper self-diagnose and misuse of drugs. Additionally, chronic constipation leads to hemorrhoids and other lower gastrointestinal tract disorders, which is considered a risk factor for colorectal cancer. It has been known that the less frequent defecations allow carcinogens in stool to contact with the intestinal wall longer and increase the probability of colorectal cancer. Among 17 million colorectal cancer patients, 1 out of every 7 patients have experienced constipation before they were diagnosed with cancer. ${ }^{2}$

According to a systematic review on diagnosis of constipation

Received January 29, 2015, Revised March 24, 2015, Accepted March 24, 2015

Correspondence to: Ae-Son Om

Department of Food and Nutrition, College of Human Ecology, Hanyang University, 222 Wangsimni-ro, Seongdong-gu, Seoul 133-791, Korea Tel: +82-2-2220-1203, Fax: +82-2-2220-1856, E-mail: aesonom@hanyang.ac.kr, ORCID: Ae-Son Om, http://orcid.org/0000-0002-9452-9647

Copyright (C) 2015 Korean Society of Cancer Prevention

(c) This is an Open Access article distributed under the terms of the Creative Commons Attribution Non-Commercial License (http://creativecommons. org/icenses/by-nc/3.0) which permits unrestricted non-commercial use, distribution, and reproduction in any medium, provided the original work is properly cited. 
by the Korean Society of Gastroenterology, constipation is categorized into five groups due to its pathophysiology. The first category consists of patients who are constipated since they consume less than adequate amount of food required to produce feces. Hence, constipation of this type occurs mainly in young women dieting to lose and/or manage their body weight. Insufficient food intake decrease moisture content of the stool and increase colonic transit time. ${ }^{3}$ The constipation prevalence rate of Korean female college students, known for their vast interest in weight loss/management, ranged from $28.9 \%$ to $46.0 \%$. ${ }^{4}$ Sensitivity to stress, skipping breakfast, eating less meals, more frequent dining out habits, and insufficient water and fiber intake are also considered to be factors that can lead to constipation. $^{5}$

Dietary fiber suppresses the proliferation of intestinal pathogenic bacteria and increases the number of probiotics such as bifidobacteria and lactic acid bacteria. ${ }^{6,7}$ The recent study demonstrated the correlation between constipation prevalence rate and nutrient intakes in Korean college students. The average fiber intake in male students was $15.0 \mathrm{~g} / \mathrm{d}$ and that of female students was $13.5 \mathrm{~g} / \mathrm{d}$, which were $48.4 \%$ and $54.0 \%$ of recommended sufficient daily intake for male and female, 31.0 g/d and $25.0 \mathrm{~g} / \mathrm{d}$ respectively. ${ }^{4}$

Chicory (4\%), broccoli (2.6\%), and whole grains (whole brown rice $3.5 \%$, whole wheat $12.2 \%$, and whole barley $17.3 \%$ ) are abundant in dietary fiber. ${ }^{8}$ Seventy percent of chicory's dry weight is inulin, which is known to reach the distal colon and be fermented slowly. Supplement of $15 \mathrm{~g}$ chicory inulin for 4 weeks significantly increased the frequency of evacuation in constipated patients and caused an increase in bifidobacteria, an intestinal probiotics. ${ }^{9,10}$ Costabile et al. ${ }^{11}$ demonstrated that subjects who consumed $48 \mathrm{~g}$ whole grain cereal for 3 weeks had significantly increased numbers of bifidobacteria and lactobacillus, and evacuation frequency compared to the control group supplied with same amount of wheat bran cereal.

In order to evaluate whether Vege-Powder (VP) rich in dietary fiber has an effect on alleviating symptoms of constipation, subjects who have experienced constipation were provided with VP mainly consisted of chicory, broccoli, and whole grains for 4 weeks and temporal changes in constipation symptoms due to the dietary supplements were surveyed.

\section{MATERIALS AND METHODS}

\section{Subjects}

A survey was conducted on 200 subjects in their twenties from
Table 1. Rome II diagnostic criteria for functional constipation

At least 12 weeks, which need not be consecutive, in the preceding

12 months of two or more of:

1. Straining $>1 / 4$ of defecations:

2. Lumpy or hard stools $>1 / 4$ of defecations;

3. Sensation of incomplete evacuation $>1 / 4$ of defecations;

4. Sensation of anorectal obstruction/blockage $>1 / 4$ of defecations;

5. Manual maneuvers to facilitate $>1 / 4$ of defecations (e.g., digital evacuation, support of the pelvic floor); and/or

6. $<3$ defecations per week.

September to October 2014 based on the Rome II criteria (Table 1) to determine the presence of constipation. ${ }^{12}$ Subjects who have taken laxatives within the previous 3 months were excluded and the subjects voluntarily participated after given thorough information on the purpose of the study. Fourteen subjects dropped out due to incomplete survey questionnaire or personal reasons and a total of 96 volunteers completed this trial. The number of subjects was calculated with a calculation formula, taking the response rate into consideration. ${ }^{13}$ The study was approved by the Institutional Review Board of Hanyang University (HY-14-113-1).

\section{Study design}

This dietary intervention study was performed using a randomized-controlled, double-blind method. Subjects were randomly allocated into the control $(n=51)$ or the VP intake group $(\mathrm{n}=45)$. The dietary intervention lasted 4 weeks from October 16, 2014 to November 12, 2014 and all participants were given instructions to ingest power-formulated supplement of the same color and form. The VP group were supplied with VP, containing the three main ingredients (whole grain, chicory, and broccoli) and the control group was supplied with 'Rice Flakes-Powder' with a higher rice flake content without the three main ingredients of VP. During the experiment, the subjects ingested $30 \mathrm{~g}$ of 1 serving size twice a day (total of $60 \mathrm{~g} / \mathrm{d}$ ). VP was formulated to contain $37.9 \mathrm{~g}(63.2 \%$ of $60 \mathrm{~g})$ of dried whole grains, chicory, and broccoli powder in $60 \mathrm{~g}$ daily intake and this allowed subjects to consume $17 \mathrm{~g}$ of dietary fiber per day. This is equivalent to $55 \%$ of recommended dietary fiber intake of adult males $(31.0 \mathrm{~g} / \mathrm{d})$.

\section{Survey questionnaire}

A panel of experts in survey research reviewed logical consistencies, ease of understanding, sequence of items, and task relevance of survey questionnaire. To evaluate the effect of VP supplement on constipation alleviation, survey questionnaire 
was developed based on the survey used on Xin et al. ${ }^{14}$ Stool hardness was measured with a 5-point Likert scale, starting at 1 (watery) to 5 (very hard). Amount of stool was displayed on a scale of 1 (less than $35 \mathrm{~g}$ [half a banana]), to 5 (over $300 \mathrm{~g}$ [more than 4 bananas]), and were instructed to evaluate relatively. Sensation of incomplete evacuation and strain to defecate were also measured with the 5-point Likert scale starting at 1 (extremely severe) to 5 (very weak), and as the score increases, it indicated alleviation of symptoms. Separate evaluations were conducted for each question before supplement intake, at day 14 , and day 28 after the beginning of supplements.

\section{Statistical analysis}

Data was analyzed with IBM SPSS program ver. 21.0 (IBM Co., Armonk, NY, USA) and values are presented as mean \pm standard deviations. The difference between the control group and the VP intake group was examined with Student t-test, and analysis of temporal changes in constipation symptoms (stool hardness, amount, sensation of incomplete evacuation, and straining to defecate) due to the consumption of supplements at 3 different time points was performed using repeated measures analysis of variance (ANOVA). The relationship between ingested diets and

Table 2. General characteristics of subjects

\begin{tabular}{lrr}
\hline \multicolumn{1}{c}{ Characteristic } & \multicolumn{1}{c}{ Con } & \multicolumn{1}{c}{ VP } \\
\hline Age $(\mathrm{yr})$ & $26.3 \pm 2.8$ & $24.0 \pm 1.9$ \\
Height $(\mathrm{cm})$ & $169.5 \pm 9.7$ & $168.4 \pm 7.8$ \\
Body weight $(\mathrm{kg})$ & $62.1 \pm 11.6$ & $62.0 \pm 12.6$ \\
Body mass index $\left(\mathrm{kg} / \mathrm{m}^{2}\right)$ & $21.44 \pm 2.44$ & $21.69 \pm 2.99$ \\
\hline
\end{tabular}

Con, Rice Flakes-Powder $(\mathrm{n}=51)$; VP, Vege-Powder $(\mathrm{n}=45)$. stool shapes was analyzed with chi-square analysis. $P<0.05$ was considered statistically significant.

\section{RESULTS}

\section{The subjects' baseline demographic}

The average age of the subjects were $26.3 \pm 2.8$ years in control group, $24.0 \pm 1.9$ years in VP group, the average height in control group was $169.5 \pm 9.7 \mathrm{~cm}$ and that of VP group was $168.4 \pm 7.8$ $\mathrm{cm}$. The average body weight of the control group was $62.1 \pm 11.6$ $\mathrm{kg}$ and that of the VP group was $62.0 \pm 12.6 \mathrm{~kg}$. The subjects' baseline demographic of the control and VP group before the experiment did not show a significant difference (Table 2).

\section{Homogeneity test of dependent variables before intake of experimental diets}

Before the consumption of experimental diets, stool amount score of control group $(1.41 \pm 0.65)$ was not different from that of VP group $(1.76 \pm 0.64)$. The VP group indicated higher score of sensation of incomplete evacuation $(2.86 \pm 0.86)$ than that of the control group $(3.42 \pm 1.16)$. The strain to defecate before intake of experimental diets showed no difference between the control and VP intake group $(3.17 \pm 1.25$ vs. $3.14 \pm 1.26$ ) (Table 3).

\section{Temporal changes of constipation parameters in} subjects who received Vege-Powder supplements

The effectiveness of VP on constipation alleviation was surveyed before supplement intake, at day 14, and day 28 after the beginning of supplements on the subject's stool hardness, amount of stool, straining to defecate, with the 5-point Likert

Table 3. Profile analysis of constipation parameters in subjects who received diet supplements

\begin{tabular}{|c|c|c|c|c|c|c|}
\hline Variable & Before & Day 14 & Day 28 & \multicolumn{2}{|c|}{$F$-value } & $P$-value \\
\hline Hardness of stool* & & & & G & 5.30 & 0.024 \\
\hline Con & $1.89 \pm 1.32$ & $0.78 \pm 1.14$ & $1.00 \pm 1.30$ & $\mathrm{~T}$ & 19.93 & 0.001 \\
\hline VP & $1.97 \pm 1.32$ & $1.33 \pm 0.88^{\|}$ & $1.56 \pm 0.88^{\| \prime}$ & $\mathrm{G}^{*} \mathrm{~T}$ & 1.85 & 0.164 \\
\hline Amount of stool ${ }^{\dagger}$ & & & & G & 29.79 & 0.001 \\
\hline Con & $1.41 \pm 0.65$ & $1.45 \pm 0.72$ & $1.51 \pm 0.76$ & $\mathrm{~T}$ & 7.96 & 0.010 \\
\hline VP & $1.76 \pm 0.64^{\|}$ & $2.00 \pm 0.55^{\|}$ & $2.28 \pm 0.62^{\|}$ & $\mathrm{G}^{*} \mathrm{~T}$ & 3.72 & 0.027 \\
\hline Sensation of incomplete evacuation ${ }^{\ddagger}$ & & & & G & 8.14 & 0.005 \\
\hline Con & $3.42 \pm 1.16$ & $3.73 \pm 0.87$ & $3.85 \pm 1.10$ & $\mathrm{~T}$ & 44.15 & 0.001 \\
\hline VP & $2.86 \pm 0.86^{\|}$ & $4.46 \pm 0.66^{\| 1}$ & $4.63 \pm 0.50^{\| \prime}$ & $\mathrm{G} * \mathrm{~T}$ & 17.95 & 0.001 \\
\hline Straining to defecate ${ }^{\S}$ & & & & G & 43.41 & 0.001 \\
\hline Con & $3.17 \pm 1.25$ & $2.93 \pm 1.34$ & $2.97 \pm 1.20$ & $\mathrm{~T}$ & 8.94 & 0.001 \\
\hline VP & $3.14 \pm 1.26$ & $4.24 \pm 0.68^{\| 1}$ & $4.57 \pm 0.56^{\|}$ & $\mathrm{G}^{*} \mathrm{~T}$ & 16.82 & 0.001 \\
\hline
\end{tabular}

Values are mean \pm standard deviation. Con, Rice Flakes-Powder ( $=51$ ); VP, Vege-Powder ( $=45)$; G, group; T, time; G*T, group and time interaction. ${ }^{*}$ The rating scale from 1 to 5 is denoted as: 1 (watery), 2 (mushy), 3 (soft), 4 (hard), 5 (very hard), ${ }^{\dagger}$ The rating scale from 1 to 5 is denoted as: $1(<35 \mathrm{~g}), 2(35-80 \mathrm{~g}), 3(80-200 \mathrm{~g}), 4(200-300 \mathrm{~g}), 5(>300 \mathrm{~g})$. ${ }^{\text {f }}$ The rating scale from 1 to 5 is denoted as: 1 (extremely severe), 2 (severe), 3 (moderate), 4 (weak), 5 (very weak). "Significantly different from control group $(P<0.05)$. 


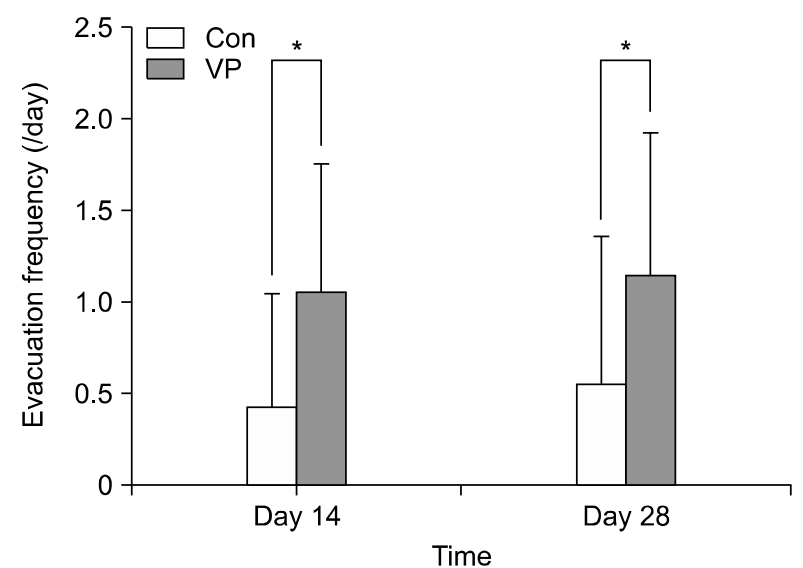

Figure 1. Evacuation frequency of subjects who received control or experimental diet supplement Values are mean \pm standard deviation. Con, Rice flake powder $(\mathrm{n}=51)$; VP, Vege-Powder $(\mathrm{n}=$ 45). *Significantly different from control group $(P<0.05)$.

scales (Table 3). There was a difference in the two group's stool hardness according to the supplemented dietary type $(P=0.024)$, however the interaction between the groups and the period of diet supplement did not significantly affect stool hardness. It was significantly affected by the period of supplements in each group $(P=0.001)$. In the control group, the rating scale of stool amount before the diet supplements was 1.41 and it was 1.51 at day 28 of dietary intake, whereas that of VP group increased from 1.76 to 2.28. Repeated measures ANOVA analysis indicated that amount of stool was significantly affected by type of dietary supplements, time, and interaction of diet and time. The score of sensation of incomplete evacuation was low in VP intake group before the experiment. Hence, before the consumption of dietary supplements, the sensation of incomplete evacuation of VP group was more severe than the control group, however at 2 weeks and 4 weeks of the study, it significantly improved compared to that of the control group as well as compared to before the experiment $(P=0.001)$. Straining to defecate also showed similar to results of the sensation of incomplete evacuation. The rating scales of straining to defecate were not different between the two groups before the study, at 2 weeks and 4 weeks of the experiment, VP group showed significantly higher score compared to the control group. Period of consumption also affected the scale of straining to defecate $(P=0.001)$. Therefore, the intake of VP supplement for 2 or 4 weeks improved the stain to defecate.

\section{The effect of vege-powder supplements evacua- tion frequency}

The evacuation frequency showed significant difference
Table 4. Chi-square analysis of stool shape in subjects who received control or VP supplement

\begin{tabular}{cccc}
\hline Variable & $\begin{array}{c}\text { No. of subjects } \\
\text { who evacuated }\end{array}$ & $\begin{array}{c}\text { Proportion of subjects } \\
\text { who observed normal } \\
\text { shape stool (\%) }\end{array}$ & $\chi^{2}$ \\
\hline $\begin{array}{c}\text { Before } \\
\text { Con }\end{array}$ & 31 & 16.13 & 0.075 \\
VP & 26 & 23.08 & \\
Day 14 & & & 3.467 \\
Con & 16 & 18.75 & \\
VP & 23 & 47.80 & $12.076 *$ \\
Day 28 & & & \\
Con & 19 & 26.32 & \\
VP & 33 & 75.76 & \\
\hline
\end{tabular}

Con, Rice Flakes-Powder $(\mathrm{n}=51)$; VP, Vege-Powder $(\mathrm{n}=45)$. *Significantly correlated by chi-square test $(P<0.05)$.

between the groups at day 14 , and day 28 after the beginning of supplements. At 2 weeks of supplement, VP group $(1.04 \pm 0.71)$ increased significantly compared to the control group $(0.41 \pm$ $0.64)$ and this difference maintained at 4 weeks of intake (VP intake group $1.13 \pm 0.79$ vs. control group $0.55 \pm 0.81$ ) (Fig. 1).

\section{Relationship of vege-powder supplement and stool shape}

Relationship of dietary supplement (control group or VP group) and stool shape was analyzed using chi-square analysis (Table 4). Total number of subjects in the control group was 51 , and the number of subjects who defecated were 31, 16, and 19 (before experiment, 2 weeks, and 4 weeks respectively). Among those who have defecated, $16.13 \%, 18.75 \%$, and $26.32 \%$ subjects indicated to defecate normal shape of stool. In VP group, there were 45 subjects, and those who answered to evacuate were 26 , 23, and 33 (before experiment, 2 weeks, and 4 weeks respectively). Among the subjects who evacuated, $23.08 \%, 47.80 \%$, and $75.76 \%$ have defecated normal shape of stool. A significant correlation was found between the subject's dietary supplement type and stool shape at 4 weeks of intake.

\section{DISCUSSION}

Constipation directly and indirectly affects $20 \%$ of the population's health. ${ }^{15}$ Additionally, constipation decreases the quality of life and increases the risk of colorectal cancer. A recent systematic review and meta-analysis reported that chronic constipation patients, compared to patients with no constipation, had a significantly higher colorectal cancer risk and the severity of chronic constipation was associated with prevalence and 
incidence of colorectal cancer. ${ }^{16}$ These results suggested that chemopreventive strategy through prevention of constipation is conceivable since chronic constipation is positively related to the risk of colorectal cancer.

Laxatives are most commonly used to alleviate constipation. ${ }^{17}$ However, frequent laxative uses have been reported to cause side effects. Lifestyle changes such as physical activities and increased intake of fluid or dietary fiber were accepted as effective methods to alleviate constipation symptoms without side effects. Soluble dietary fiber absorbs water to form a viscosity gel and is fermented by bacteria in colon. Furthermore, insoluble dietary fiber acts as an bulking agent to increase the amount of stool. ${ }^{18}$ Studies recruiting both children and adults has been demonstrated that dietary fiber supplement improved constipation symptoms. ${ }^{19,20}$ In a meta-analysis of dietary fiber and its effectiveness on constipation, it evidently revealed that supplement of dietary fiber increased evacuation frequency in constipation patients. ${ }^{21}$ Moreover, in 2011, the expert panel of the World Cancer Research Fund/American Institute for Cancer Research's Continuous Update Project concluded that there is 'convincing' evidence that consumption of foods containing dietary fiber protects against colorectal cancer. ${ }^{22}$ The results of six prospective studies dealing with whole grains, a major source of dietary fiber, and colorectal cancer indicated that increment of whole-grain intake significantly reduced colorectal cancer risk. ${ }^{23}$

This study aimed to evaluate the effects of VP, containing chicory, broccoli, and whole grains, supplement for 4 weeks on evacuation frequency and defecation characteristics. Evacuation frequency at 2 and 4 weeks of VP intake showed a significant increase compared to the control group. Chen et al. ${ }^{24}$ pointed out that subjects provided $1.5 \mathrm{~g}$ konjac glucomannan for 3 weeks showed changes in evacuation frequency from 4.1 to 5.3 times a week, and increased numbers of probiotics, such as bifidobacteria and lactobacillus, in stool samples compared to the control group. Castillejo et al. ${ }^{25}$ found that when 56 children (ages, 3-10 years) diagnosed with chronic constipation were administrated a supplement of cocoa husk for 4 weeks, the intestinal transit time was reduced and bowel movements was stimulated compared to the control group. In this study, VP mainly consisting of chicory, broccoli, and whole grains exhibited significant effects after 2 weeks of consumption, suggesting that VP supplement was capable to increase evacuation frequency relatively faster than the supplement of dietary fiber derived from single ingredient. This is speculated that not only the dietary fibers but also inulin, proteins, calcium, and polyphenols of chicory, broccoli, and whole grains play a role in alleviating constipation.
Inulin in chicory is known to improve gut microbiota and stimulate bowel movement. Den Hond et al. ${ }^{9}$ supplied constipation patients with $15 \mathrm{~g}$ of chicory inulin per day for 2 weeks and found that subjects consumed chicory inulin, compared to the control group, showed significant increase in evacuation frequency and amount of stool. Hence, $1 \mathrm{~g}$ of chicory inulin intake increased dry stool amount by $1.5 \mathrm{~g}$. Marteau et al. ${ }^{10}$ also demonstrated that supplement of $15 \mathrm{~g}$ chicory inulin for 2 weeks to constipation patients resulted in increase in evacuation frequency (4.9 to 7.0 times), and $82 \%$ of chicory inulin group experienced bowel movement whereas $25 \%$ of the control group did. Additionally, 4 weeks of chicory inulin intake significantly increased bifidobacteria in stool samples. Therefore, it can be inferred that inulin in chicory positively affected constipation alleviation due to the consumption of VP in this study.

The measurements of stool amount observed by study participants are hard to be objective, especially in case of soft stools, as it has been complicated to measure the volume of the stool. Therefore, the results of stool amount has a margin of error, however as subjects observed and recorded repeatedly over time, it could have been used as a relative comparative value to speculate changes. In this study, changes of amount of stool in the control group were not noticeable during diet supplements, whereas VP group observed significant increases in stool amount. This result confirms that dietary fibers of VP served as a bulking agent.

It should be pointed out that we found significant differences in the indicators of bowel evacuation habits between the control and VP groups at 2 and 4 weeks of supplements, as well as significant differences in accordance with the period of supplement in VP group. The frequency of evacuation of VP group at 2 weeks significantly increased compared to that of the control group and this difference persisted at 4 weeks. Based on these findings, mechanisms by which VP alleviates constipation symptoms are speculated that the soluble dietary fibers in chicory, broccoli, and whole grains suppressed harmful microorganisms in the colon and accelerate the proliferation of probiotics such as bifidobacteria and lactic acid bacteria and insoluble dietary fiber increase the amount of stool. Moreover, synergistic effects of nutrients found in vegetables, such as inulin, proteins, calcium, and polyphenols, are assumed to contribute to alleviating constipation symptoms.

In summary, we observed that VP supplement for 4 week, mainly consisted of chicory, broccoli, and whole grains, improved bowel movements (stool hardness, amount of stool, sensation of incomplete evacuation, and straining to defecate) compared to 
the control group.

\section{CONFLICTS OF INTEREST}

No potential conflicts of interest were disclosed.

\section{REFERENCES}

1. Bharucha AE, Pemberton JH, Locke GR 3rd. American Gastroenterological Association technical review on constipation. Gastroenterology 2013;144:218-38.

2. Jun DW, Park HY, Lee OY, Lee HL, Yoon BC, Choi HS, et al. A population-based study on bowel habits in a Korean community: prevalence of functional constipation and self-reported constipation. Dig Dis Sci 2006:51:1471-7.

3. Myung SJ, Lee TH, Huh KC, Choi SC, Sohn CI; Korean Society of Neurogastroenterology and Motility. Diagnosis of constipation: a systematic review. Korean J Gastroenterol 2010;55:316-24.

4. You JS, Chin JH, Chang KJ. Prevalence of constipation, bowel habits and nutrient intakes of college students in incheon area. Korean J Nutr 2009:42:702-13.

5. Sung MJ, Chang KJ. Correlations among life stress, sleep, anthropometric measurement and nutrient intakes of college students. J Korean Soc Food Sci Nutr 2007:36:840-8.

6. Quigley EM. The enteric microbiota in the pathogenesis and management of constipation. Best Pract Res Clin Gastroenterol 2011;25:119-26.

7. Velázquez M, Davies C, Marett R, Slavin JL, Feirtag JM. Effect of oligosaccharides and fibre substitutes on short-chain fatty acid production by human faecal microflora. Anaerobe 2000;6:87-92.

8. U.S. Department of Agriculture (USDA). USDA National Nutrient Database for Standard Reference, Release 26, Nutrient Data Laboratory. Available from: http://www.ars. usda.gov/ba/bhnrc/ndl. Accessed 2013.

9. Den Hond E, Geypens B, Ghoos Y. Effect of high performance chicory inulin on constipation. Nutrition Research 2000;20:731-6.

10. Marteau P, Jacobs H, Cazaubiel M, Signoret C, Prevel JM, Housez B. Effects of chicory inulin in constipated elderly people: a double-blind controlled trial. Int J Food Sci Nutr 2011:62:164-70.

11. Costabile A, Klinder A, Fava F, Napolitano A, Fogliano V, Leonard C, et al. Whole-grain wheat breakfast cereal has a prebiotic effect on the human gut microbiota: a double-blind, placebo-controlled, crossover study. Br J Nutr 2008;99:110-20.

12. Thompson WG, Longstreth GF, Drossman DA, Heaton KW, Irvine EJ, Muller-Lissner SA. Functional bowel disorders and functional abdominal pain. Gut 1999:45 Suppl 2:II43-7.

13. Food and Agriculture Organization of the United Nations (FAO). Conducting small-scale nutrition surveys: a field manual. Nutrition in Agriculture. No. 5. Rome, FAO, 1990.

14. Xin HW, Fang XC, Zhu LM, Xu T, Fei GJ, Wang ZF, et al. Diagnosis of functional constipation: agreement between Rome III and Rome II criteria and evaluation for the practicality. J Dig Dis 2014:15:314-20

15. Higgins PD, Johanson JF. Epidemiology of constipation in North America: a systematic review. Am J Gastroenterol 2004:99:750-9.

16. Guérin A, Mody R, Fok B, Lasch KL, Zhou Z, Wu EQ, et al. Risk of developing colorectal cancer and benign colorectal neoplasm in patients with chronic constipation. Aliment Pharmacol Ther 2014:40:83-92.

17. Xing JH, Soffer EE. Adverse effects of laxatives. Dis Colon Rectum 2001;44:1201-9.

18. Anderson JW, Baird P, Davis RH Jr, Ferreri S, Knudtson M, Koraym A, et al. Health benefits of dietary fiber. Nutr Rev 2009;67: 188-205.

19. Kranz S, Brauchla M, Slavin JL, Miller KB. What do we know about dietary fiber intake in children and health? The effects of fiber intake on constipation, obesity, and diabetes in children. Adv Nutr 2012;3:47-53.

20. Marlett JA, McBurney MI, Slavin JL; American Dietetic Association. Position of the American Dietetic Association: health implications of dietary fiber. J Am Diet Assoc 2002;102:993-1000.

21. Yang J, Wang HP, Zhou L, Xu CF. Effect of dietary fiber on constipation: a meta analysis. World J Gastroenterol 2012;18:7378-83.

22. World Cancer Research Fund, American Institute for Cancer Research. Continuous update project report. Food, nutrition, physical activity, and the prevention of colorectal cancer. London, World Cancer Research Fund International. 2011.

23. Aune D, Chan DS, Lau R, Vieira R, Greenwood DC, Kampman E, et al. Dietary fibre, whole grains, and risk of colorectal cancer: systematic review and dose-response meta-analysis of prospective studies. BMJ 2011:343:d6617.

24. Chen HL, Cheng HC, Wu WT, Liu YJ, Liu SY. Supplementation of konjac glucomannan into a low-fiber Chinese diet promoted bowel movement and improved colonic ecology in constipated adults: a placebo-controlled, diet-controlled trial. J Am Coll Nutr 2008:27:102-8.

25. Castillejo G, Bulló M, Anguera A, Escribano J, Salas-Salvadó J. A controlled, randomized, double-blind trial to evaluate the effect of a supplement of cocoa husk that is rich in dietary fiber on colonic transit in constipated pediatric patients. Pediatrics 2006; 118:e641-8. 